\title{
Repensando la adopción internacional desde un enfoque centrado en el menor: el caso de España-Etiopía
}

\section{Rehinking international adoption from a children-focused perspective}

\author{
Aranzazu Gallego Molinero \\ Universidad de Granada \\ aranzazu@ugr.es
}

Recibido: $11 / 10 / 2011$

Revisado: 02/11/2011

Aceptado: 15/07/2012

Disponible on line: 16/04/2013

\section{Resumen}

El presente artículo apuesta por la reflexión no adulto-céntrica sobre la adopción internacional de niños y niñas etíopes en España. Analizamos críticamente, con un enfoque basado en los derechos de la infancia aplicado a la adopción internacional como tales prácticas, en la actualidad, no responden a los principios básicos del interés superior del menor, la subsidiariedad y posibilidad de adopción de niños y niñas, que son preceptivos en la normativa internacional y en las legislaciones internas de España, y Etiopía.

Palabras clave: adopción internacional, Etiopía, España, derechos de los niños/as.

\begin{abstract}
This article aims at a non adult-centric reflection about international adoption of Ethiopian children in Spain. From an approach based on children's rights applied to international adoption, we offer a critical analysis on how these practices do not respond nowadays to the basic principles of best interest of the child, subsidiarity, and adoptability of the children, which are the ruling principles in international rules and national legislation in Spain and Ethiopia.
\end{abstract}

Keywords: international adoption, Ethiopia-Spain, children's rights.

Referencia normalizada: Gallego Molinero, A. (2013): «Repensando la adopción internacional desde un enfoque centrado en el menor: el caso de España-Etopía:. Cuadernos de Trabajo Social, 26(1): 203-212.

Sumario: Introducción. 1. Los menores en el proceso adoptivo como sujetos de derechos. 2. Los menores en el proceso adoptivo como sujeto de protección. 3. Los menores adoptados como sujetos de promoción. 4. Consideraciones finales. 5. Referencias bibliográficas.

\section{Introducción}

En este artículo nos proponemos abordar la adopción internacional, enfocando la mirada en los derechos de la infancia, cuestionando el adulto-centrismo que no toma en consideración a los niños como sujetos que lo protagonizan, así como los retos que conlleva.

Diferentes autores señalan que el planteamiento dominante en nuestra sociedad sobre la adopción internacional la concibe como un medio para ser padres, ocupando el deseo de los adultos una posición central. En consecuencia prevalece «ser padre o padres» sobre la necesidad de hallarles una familia a niños y niñas adoptables. Todo ello en detrimento de los derechos y bienestar de los niños y niñas
(Berátegui, 2005, 2009, 2010; Montané, 1996; Marre, 2010; entre otros).

El enfoque de derechos aplicado a la niñez implica un cambio de perspectiva sustancial, en tanto que es el niño quien tiene la necesidad y la familia adoptante es concebida como el recurso de protección adecuado para cubrir sus necesidades.

Con la entrada en vigor de la Convención de los Derechos del Niño de 1989 asistimos a un cambio de perspectiva en la consideración de los menores como sujetos de derechos que poseen como personas, por lo que adquieren pleno estatus social como poseedores de dichos derechos (Verhellen, 1992; Therborn, 1993; Casas, 1998). 
El niño y la niña dejan de ser los receptores pasivos, pasando a ser sujetos o titulares de sus derechos, lo que implica que no son «propiedad» de sus padres ni los beneficiarios indefensos de una obra asistencial-benéfica (UNICEF).

Desde el punto de vista del menor y la nueva perspectiva marcada por la Convención, las pretensiones van encaminadas a desprenderse de valores adulto-céntricos, entendiendo la adopción como una medida de protección, que deberá regirse por la búsqueda del interés superior del niño y el respeto a sus derechos fundamentales.

En el contexto africano, la Convención de los Derechos de los Niños se complementa con la Carta Africana sobre los Derechos y el Bienestar del Niño, uniéndose a la filosofía de la Convención que los considera sujetos de derechos. Sin embargo, por lo que respecta a Etiopía, en la actualidad aún no es un país signatario del Convenio de la Haya relativo a la protección del Niño y Cooperación en materia de Adopción Internacional.

Como órganos de supervisión, señalamos el Comité de los Derechos del Niño que exhorta a todos los gobiernos que han ratificado el tratado a que presenten informes sobre la situación de los derechos de la infancia en sus respectivos países. En el contexto africano, el Comité Africano de Expertos en los Derechos y el Bienestar del Niño vigilará el cumplimiento de la Carta Africana.

Los tres instrumentos a los que haremos referencia en las siguientes páginas son: la Convención sobre los Derechos del Niño, la Carta Africana sobre los Derechos y el Bienestar del Niño, y el Convenio de La Haya relativo a la Protección del Niño y la Cooperación en materia de Adopción Internacional. Con la mención a los estudios e informes de otras organizaciones influyentes con sedes en Etiopía, como el Fondo de las Naciones Unidas para la Infancia (UNICEF), el Centro Internacional de Referencia para los Derechos del Niño Privado de Familia del Servicio Social Internacional y la Alianza Internacional Save the Children, entre otras.

\section{Los menores en el proceso adoptivo como sujetos de derechos}

La dinámica de fortalecimiento de los derechos de ciudadanía de la mujer y de diversos grupos oprimidos genera un contexto favorable para el surgimiento de la consideración del niño como sujeto de derechos (Piloti, 2000). Si en una época la atención a las necesidades y problemas de los niños y niñas se consideraron actos graciables dirigidos a aquellos que se hallan en situación de marginación social, ahora se han convertido en derechos jurídicamente vinculantes que poseen como personas y ciudadanos. Protección, provisión y promoción son los ejes sobre los que pivotan las necesidades y los derechos contenidos en la Convención de los Derechos del Niño. La Convención lo destaca como el instrumento más aceptado a nivel mundial - excepto en Somalia y Estados Unidos - lo que apunta a un consenso significativo entre países (ídem). Señala como personas menores de edad a «todo ser humano menor de dieciocho años de edad, salvo, que, en virtud de la ley que le sea aplicable, haya alcanzado antes la mayoría de edad» (art. 1). Destacamos la consideración, en tanto que estamos tratando a la infancia a nivel internacional y concretamente para el caso de Etiopía, de que las personas menores de edad tienen los mismos derechos, independientemente de su «nacionalidad».

El interés superior del menor se constituye como principio rector y guía, que es reflejo de la evolución reconocida en la concepción de los tratados internacionales de los derechos del niño y de la niña. La citada Convención establece en su primer párrafo que:

En todas las medidas concernientes a los niños que tomen las instituciones públicas o privadas de bienestar social, los tribunales, las autoridades administrativas o los órganos legislativos, una consideración primordial a que se atenderá será el interés superior del niño (art. 3).

Las críticas más frecuentes de los expertos señalan que se trata de un principio abierto e indeterminado, y argumentan que la interpretación final puede quedar bajo la discrecionalidad de la persona, institución o autoridad que la aplique en situaciones concretas (Alston, Gilmour-Walsh, 1999).

Desde la perspectiva de la diversidad cultural, nos encontramos con serias complejidades en la aplicación del principio del interés superior del niño. Refiriéndose a este tema, Alston reconoce que el significado de este principio 
puede adquirir connotaciones distintas en contextos culturales diferentes (Alston GilmourWalsh, 1999: Piloti, 2000).

Por lo que respecta al continente africano, en 2008 se celebró el Foro Africano de Políticas de Infancia, cuya temática versó sobre In the best interests of the child: Harmonisation of Laws on Children in Eastern and Southern Africa. Si bien, como señala Mezmur (2010), los esfuerzos de armonización se encuentran en curso en varios países africanos, en otros países como el caso de Etiopía aún queda por hacer.

Cabe señalar que el principio del interés superior del menor, revela matices que evidencian la tensión entre universalidad y relatividad, como ha señalado Piloti, lo cual estaba también presente en las consideraciones de los redactores de la Convención (ídem). Interesantes son las reflexiones que tomamos prestadas de la profesora Marre (2010) cuando señala ¿hasta qué punto podemos aplicar «el mejor interés del menor» desde una perspectiva ética y moral?, ¿son siempre capaces los adultos de anteponer el «superior interés del menor» al propio?

La referencia expresa a la adopción y los principios básicos que deben regirse las decisiones de la adopción tanto nacional o internacional de un niño o una niña queda recogida en el artículo 21 de la mencionada Convención, correspondiéndose al artículo 24 en la Carta Africana. Comentamos la apreciación de que el borrador de este artículo comenzaba con una referencia a la obligación de los Estados Partes de «facilitar» la adopción. No obstante, cuando el texto iba a pasar la segunda lectura, la Declaración de las Naciones Unidas ya se había aprobado (1986) y se habían dado una gran cantidad de casos de abusos y prácticas ilícitas en relación con la adopción internacional. Como resultado, en la versión final de este artículo, si bien se reconoce que «la adopción en otro país puede ser considerada como otro medio de cuidar del niño», se modificó por completo su redacción inicial para destacar el deber de los Estados Partes de garantizar «que el interés superior del niño» sea «la consideración primordial» en cualquier adopción y de hacer que se respeten plenamente las normas y los procedimientos establecidos (UNICEF, 1999).

Mezmur (2009), analista africano, tras una lectura atenta del artículo 21 de la Convención, nos desvela que fue cuidadosamente redactado quedando del modo: «los Estados Partes que reconocen o permiten el sistema de adopción»; mientras que el artículo 24 de la Carta Africana hace referencia a «los Estados Partes que reconocen la institución de la adopción». Las negociaciones preparatorias de la Convención, culminaron en especificar «reconocen o permiten» en respuesta a las intervenciones de varios países islámicos que no reconocen el concepto de adopción (p. 91).

El interés superior del niño, unido al principio de subsidiaridad de la adopción, constituyen dos ejes fundamentales. El principio de subsidiaridad, aplicado al procedimiento de adopción internacional, implica que sólo se debe plantear cuando se haya demostrado que no se dispone de una familia alternativa u otro medio de cuidado adecuado para el niño y niña en su país de origen (art. 20.1).

Es innegable la existencia de menores en situación de pobreza extrema y severa, si bien no todos necesitan una familia, porque la tienen. De hecho, como se ha denunciado, existe un número cada vez mayor de los mismos que han sido adoptados y no necesitaban una familia sustitutiva. Podían haber continuado creciendo con su familia biológica, si se les hubiera ofrecido un modesto apoyo o si la demanda occidental de tener hijos no ejerciera tanta presión, observándose que el principio de subsidiaridad queda vulnerado con frecuencia (Saclier, 1999).

$\mathrm{Al}$ respecto, el Convenio de La Haya convierte el principio de subsidiariedad en una norma, reconociendo que «la adopción internacional ofrece la ventaja de dar una familia permanente a un niño que no puede encontrar una familia adecuada en su Estado de origen». Este Convenio refleja la política recomendada a nivel internacional en relación con las diferentes medidas de atención a las niñas, reconociendo la singularidad de cada una y decisiones que vayan a afectar a su vida deben basarse en el respeto de esta naturaleza única de cada menor (UNICEF, 1999).

Establece así también, la siguiente jerarquía de opciones, con el fin de salvaguardar el «interés superior» del niño (ídem):

- Las soluciones familiares se preferirán, por norma general, al internamiento en instituciones.

- Las soluciones permanentes (regreso a la familia biológica, adopción) se preferirán a 
las provisionales (internamiento en instituciones, hogares de guarda o acogimiento).

- Las soluciones nacionales se preferirán a las internacionales (adopción internacional).

Continúa la Convención señalando que los Estados Partes deberán tomar las medidas necesarias para impedir el secuestro, la venta o la trata de niños (art. 35) Desde diversas instancias se denuncian los abusos en la adopción y la violación de los derechos del menor, entre los que figuran el secuestro de los mismos, la intimidación de los padres, el pago de sobornos y la falsificación de documentos, entre otros. Para abordar estos problemas se han elaborado documentos, como el Protocolo Facultativo de la Convención relativo a la venta de niños, la prostitución infantil y la utilización de niños en la pornografía (2000). Esta preocupación por el incumplimiento de las normas va unida a la regulación de los procedimientos, no obstante se van desarrollando nuevos métodos capaces de eludir las normas y leyes establecidas con el fin de satisfacer la creciente demanda de menores para adopción ${ }^{1}$.

El derecho de los niños y niñas a una identidad, al registro e inscripción de nacimiento es una buena medida para reducir su tráfico. Según UNICEF son millones aquellos y aquellas cuyo nacimiento queda sin registrar, negándoseles el derecho a una identidad oficial, un nombre reconocido y una nacionalidad. Los menores que «no existen» jurídicamente son particularmente vulnerables al tráfico infantil y la adopción ilegal. Según la disposición de la Convención de los Derechos del Niño (art. 8), se trata de un derecho humano fundamental que abre el camino a los demás derechos, como el derecho a la educación y a los cuidados médicos, a la participación y a la protección.

En Etiopía, el Código de la Familia (2000), reconoce el registro de nacimiento a nivel local, es decir del Kebele ${ }^{2}$. Desde el año 2004, el Gobierno de Etiopía ha instituido programas-piloto de registro de nacimientos en diferentes regiones del país, con la finalidad de establecer un sistema nacional de registro civil. En cuanto al derecho que establece la Convención de los Derechos del Niño: «en la medida de lo posible, a conocer a sus padres y a ser cuidado por ellos»» (art. 7), especial tratamiento han de tener los niños y niñas en situación de emergencia debido a desastres naturales o conflictos bélicos, prohibiendo la normativa internacional que estos menores sean adoptados. Cuando los menores están separados de sus padres o son refugiados se han de realizar todas las gestiones pertinentes para la localización de la familia, y trabajar sobre las condiciones para que en un futuro cercano pueda darse la reunificación familiar ${ }^{3}$.

En países en conflicto armado, como la República del Congo, se procedió a la suspensión de las adopciones internacionales y también se suspendieron en Nepal por las irregularidades constatadas de la existencia de la familia biológica, que ponían en peligro el interés del niño. Otro de los casos más recientes es el del devastador terremoto acontecido en Haití. Estos casos informan de que la adopción internacional no es un recurso o una respuesta apropiada en un contexto de crisis, como ha sido ampliamente reconocido en los textos internacionales por los especialistas en la protección de la infancia y organismos oficiales como UNICEF o Save the Children, entre otros.

Gómez (2010) estudia las razones por las que se impide la adopción en tales circunstancias. Una de ellas tendría que ver con las motivaciones de los posibles adoptantes. Ser padres es una decisión que se ha de madurar y reflexionar en tanto que tal opción es para toda la vida, siendo un riesgo el que se base en impulsos solidarios antes imágenes de sufrimiento que nos ofrecen los medios de comunicación.

1 UNICEF (1999) reúne en una lista inacabada la diversidad de métodos empleados y el gran número de personas que pueden llegar a intervenir en el proceso, así también manifiesta, que «en muchos de estos casos, por no decir en la mayoría, la adopción presenta las características formales propias de un procedimiento perfectamente legal. Por este motivo, resulta prácticamente imposible ofrecer una lista completa de los abusos que se cometen».

2 Del amárico Kebele, se puede traducir por «barrio», es la unidad administrativa más pequeña en Etiopía.

3 A modo de ejemplo, citamos las consecuencias devastadoras del Tsunami en 2004, cuando hubo 1.709 niños separados de su familia, 1.605 de los cuales se reunieron con su familia cercana en Tailandia (Centro Internacional de Referencia para los Derechos del Niño Privado de Familia del Servicio Social Internacional, 2008b, p.2). 
Otra razón sería la necesaria declaración de adoptabilidad de los niños, y en estas situaciones es imposible poder constatar y comprobar la situación personal y familiar de los niños y su condición de adoptables (2010); unido, a que cualquier acción que tenga como objetivo adoptar o trasladar a otro país a los niños víctimas de una catástrofe puede ser perjudicial para ellos. Siguiendo a Gómez:

¿Está preparado para la adopción internacional un niño que ha sufrido un terremoto, la destrucción de su casa y la separación de su familia que, en muchos casos ni siquiera existe constancia de si ha muerto o si está aún buscándole?

Podemos relacionar, el artículo 8 de la Convención de los Derechos del Niño, con el derecho a conocer la verdad acerca de sus orígenes, a sus raíces étnicas, su historial médico (art. 7). En esta dirección se pronuncia el Convenio de La Haya al establecer que los Estados Contratantes deberán asegurar la conservación de «la información de la que dispongan relativa a los orígenes del niño» (art. 30). Tal y como han demostrado distintos estudios, así como las reivindicaciones por parte del colectivo de adoptados adultos, el menor adoptado necesita conocer la mayor información posible sobre su verdadera identidad para desarrollar una personalidad equilibrada.

La consideración de la conveniencia de dar continuidad a los orígenes étnicos, culturales, lingüísticos y religiosos queda recogida en el artículo 20.3 de la Convención. Esta recomendación la retoma la Carta Africana, en el preámbulo (7.a) en el que se afirma tener en cuenta, «las virtudes de su herencia cultural [de los estados miembros africanos], los antecedentes históricos y los valores de la civilización africana, que deberían inspirar y reflejarse en el concepto de los derechos y el bienestar del niño». Sin embargo, el texto del artículo 20 no exige explícitamente «continuidad (...) en el origen $(. .$.$) del niño», sino que valora la con-$ veniencia de que se preste particular atención a que haya continuidad en la educación y el origen del niño (Mezmur, 2009, p.89).

\section{Los menores en el proceso adoptivo como sujeto de protección}

En las anteriores páginas expusimos que el planteamiento filosófico de la Convención pre- tende desprenderse de valores paternalistas y autoritarios, cambio reflejado en tanto que al niño y niña se le reconoce como sujeto versus objeto de derechos y que siguen la consigna, conocida en argot internacional de las «tres pes» -Protección, Provisión y Participaciónprincipios que se corresponde con el articulado de la Convención (Verhellen, 1992; Wintersberger, 1994). La protección se refiere al derecho de recibir cuidados y derecho a ser protegido contra determinadas acciones de abandono, malos tratos, explotación por los padres o guardadores y por las instituciones o Estado. La necesidad de proteger a los niños surgió tras la industrialización, dándose las primeras discusiones sobre las responsabilidades públicas y legislativas en relación a la prohibición del trabajo infantil, la obligatoriedad de la educación y defensa contra el abuso, explotación y maltrato. En los países desarrollados la provisión de servicios y oferta de recursos para la infancia se produce con la expansión de los Estados de bienestar. La novedad importante en la Convención, lo constituye el principio de participación de los niños y niñas, estando aún como proyecto a realizar.

A continuación nos centraremos en la protección en los procesos adoptivos para posteriormente tratar la participación del menor. Entendemos que la protección hace referencia a la necesidad de aplicar medidas para proteger al menor en situación de desamparo. Ahora bien, no todos lo menores en situación de desprotección son adoptables. El Centro Internacional de Referencia para los Derechos del Niño Privado de Familia del Servicio Social Internacional aprueba la definición de Cantwell del término «adoptable», que se refiere a un niño que es «oficialmente reconocido que tiene una condición jurídica que permite que se le considere para adopción, y que se estima que requiere y es potencialmente susceptible del beneficio de tal medida» (citado en Centro Internacional de Referencia para los Derechos del Niño Privado de Familia del Servicio Social Internacional, 2008, p. 2).

En nuestra sociedad existen una serie de ideas preconcebidas sustentadas en creencias erróneas, e incluso algunas de ellas con ciertos tintes de prejuicios, y lo que es peor, de seguir de acuerdo a esas ideas preconcebidas nos acabará pasando factura cuando el menor adopta- 
do nos pregunte sobre su pasado, sus orígenes

Algunas de estas creencias o mitos ya han sido desmontadas desde diferentes instancias. A modo de ejemplo, el Centro Internacional de Referencia para los Derechos del Niño Privado de Familia del Servicio Social Internacional dedica la publicación de un boletín a desvelar cuáles son los mitos relativos al número de niños adoptables y expone la necesidad de una mayor precisión en el momento de determinar quién es adoptable, para implementar así políticas públicas más adaptadas $\mathrm{y}$, por ende, la realización de buenas prácticas institucionales y sociales.

En la actualidad el perfil mayoritario de menores susceptibles de ser adoptables responde a niños mayores de cinco años con necesidades especiales, o a grupos de hermanos. Sin embargo, existe un alto porcentaje de familias españolas que tramitan su adopción, con una declaración de idoneidad para niños y niñas de 0 a 3 años, sanos, y huérfanos. Nos encontramos ante una desproporción entre solicitantes bastante superior al número de menores posibles de ser adoptados internacionalmente (Cantwell, 2003; Berástegui, 2009, 2010; Gómez, 2010). Se estima que por cada niño pequeño y sano en condiciones de ser adoptado en el mundo, hay más de seis expedientes por adopción (San Román, 2008).

Los analistas exponen las consecuencias tan inquietantes que está provocando este «desequilibrio» en términos de «oferta y demanda». Nos hallamos ante una gran presión que impulsa a localizar a niños y niñas de las características demandadas y posteriormente a declarar su «adoptabilidad» y no a la inversa; nos encontramos con casos de padres biológicos que han sido presionados o engañados, o de menores secuestrados a sus familias ${ }^{4}$. Aumentan los casos de corrupción, en países que no contaban con mecanismos de control suficientes, nacen intermediarios sin escrúpulos o los llamados «buscadores de niños y niñas» (Cantwell, 2003; Centro Internacional de Referencia para los Derechos del Niño Privado de Familia del Servicio Social Internacional, 2004; San
Román, 2008; Berástegui, 2009,2010; Gómez, 2011, entre otros).

Los países de origen de los menores quedan colapsados de expedientes, se enduren los requisitos que han de cumplir los adoptantes, se alargan en número y tiempo las listas de espera, y los adoptantes cambian de país o solicitan doble expediente de adopción. Los países de acogida buscan otros nuevos dónde adoptar, y particularmente África pasa a ser uno de los principales países para las adopciones internacionales (Centro Internacional de Referencia para los Derechos del Niño Privado de Familia del Servicio Social Internacional, 2008a, 2008b).

Tal como se recogen en las estadísticas, Etiopía se convierte en uno de los países con un número mayor de expedientes de adopción internacional. En parte porque responde al planteamiento de que hay muchos niños huérfanos y desamparados, que se mueren de hambre, a lo que se une que los plazos de tramitación son cortos y se resuelve con rapidez. En las redes del ciberespacio - foros, redes sociales, listas de correo electrónico, webs, etc.de familias que están en trámite de adopción, las preguntas que formulan «los preadoptantes se basan prácticamente hacia cuatro objetivos fundamentales: menos tiempo, menos costes, menos trámites y mayor adecuación de la asignación a la demanda». Esta reflexión la realiza la experta en adopciones, Berástegui (2010), en un acertado análisis con la perspectiva centrada en la cultura consumista de la adopción y que podría resumirse con la siguiente frase: «¿Por qué habiendo tantos niños sufriendo injusticias en el mundo no consiguen deprisa y con pocos costes para mí, que lo necesito, uno pequeño, sano y sin traumas?» (p. 32).

Lo expuesto anteriormente pasa a ser una prioridad en la decisión adoptiva en detrimento de otras cuestiones de gran relevancia ante la decisión de tener un hijo/a, como son las garantías en la adopción, si es un Estado miembro del Convenio de La Haya, condiciones del menor y adoptabilidad, preparación e implicaciones de una adopción interracial, entre otros. Aunque Etiopía hasta la fecha no es miembro,

${ }^{4}$ Conocido es el caso de la asociación francesa El Arca de Zoé acusados de secuestro, cuando fue detenido en el Chad el avión donde transportaban a 103 niños. Organizaciones influyentes, como el Fondo de las Naciones Unidas para la Infancia (UNICEF) y el Alto Comisionado de las Naciones Unidas para los Refugiados (UNHCR/ACNUR), emitieron informes denunciando tales hechos de corrupción en el año 2007. 
el Convenio de La Haya recoge el compromiso de los países firmantes de comprobar la adoptabilidad de los menores, constatándose, después de haber examinado adecuadamente las posibilidades de colocación de la niña o niño en su Estado de origen, que una adopción internacional responde al interés superior de éstos. Velar porque las personas, autoridades e instituciones, cuyo consentimiento se requiera, hayan sido convenientemente asesoradas y debidamente informadas de las consecuencias de su consentimiento, en particular en relación al mantenimiento o ruptura, en virtud de la adopción, de los vínculos jurídicos entre el niño y su familia de origen. Así también, velar porque se den los consentimientos informados, libres, por escrito y sin ningún tipo de compensación o pago. Recoge, además, que la madre debe consentir en la adopción después del nacimiento, y que no debe existir contacto entre los futuros padres adoptivos y los padres del niño hasta que se haya determinado la adoptabilidad y se hayan prestado los consentimientos oportunos (art. 4 del Convenio de La Haya).

La situación de adoptabilidad no tiene solamente un carácter jurídico, incorpora además elementos médico-psico-sociales que han de ser estudiados y valorados y establecer una propuesta de intervención que la situación socio-familiar y el interés superior del menor recomienden la aplicación de la adopción internacional como la mejor opción para su protección. Constituyéndose la adopción internacional como una medida a la que se recurre como último recurso, en consonancia con lo que dicta el principio de subsidiariedad.

Los datos del menor, así como el análisis, valoración y propuesta de medida, deben registrarse en un informe, así lo recoge el Convenio de La Haya (art. 16). En la práctica, los expedientes de los niños/as suelen ser bastantes incompletos, y lo que es más grave, los datos contenidos en el mismo no suelen corresponderse con la realidad del niño, y queda falseada su verdadera historia de vida.

En el caso de Etiopía, el expediente del menor es recibido en el país de acogida por la Entidad Colaboradora en Adopción Internacional
(ECAI) al objeto de continuar con los trámites de la preasignación del menor (matching). El expediente del menor no sólo es de utilidad para establecer esta preasignación, sino que lo es también para tener los datos a considerar en el periodo de acoplamiento e integración del menor con la familia adoptiva - esto es de gran importancia y suele ignorarse - para que el menor ejerza su derecho al conocimiento de sus orígenes, a través del la información sobre su historia personal y familiar contenida en el mismo. Además, las autoridades competentes en la adopción deberán asegurar y conservar la información de que dispongan relativa a los orígenes del niño e identidad de sus padres, así como la historia médica del niño y de su familia (art. 30.1 del Convenio de La Haya).

Cada vez hay más familias españolas que, una vez adoptados a sus hijos/as etíopes, comienza a interesarse y a movilizarse para investigar y conocer la verdadera historia de la familia biológica de sus hijos e hijas ${ }^{5}$. Las familias se están concienciando de que un niño y niña no nace cuando lo adoptamos, tiene una historia previa que no podemos obviar y es un pilar elemental en la construcción de la historia del menor que se haya constituido una adopción de forma legítima y transparente (Casalilla, 2010).

Siguiendo a San Román (2009):

El número de familias que descubren con horror que sus adopciones no fueron limpias crece de año en año. En ocasiones, son los mismos adoptantes quienes, pensando que algún día sus hijos necesitarían saber, han tirado del hilo hasta descubrir las mentiras de sus papeles oficiales. Tal era el caso de las dos madres adoptivas que en las jornadas «La adopción internacional: el allá y el aquí» celebradas en febrero de 2008 denunciaron públicamente cómo, aunque en los papeles oficiales que les entregó la ECAI sus hijos figuraban como huérfanos, los niños que adoptaron en Etiopía resultaron no serlo. Pero también abundan los relatos en los que han sido los propios niños quienes tienen una historia que contar que en nada se parece a la versión que contiene su documentación oficial. Niños y niñas que llegan con una cierta edad y que, cuando aprenden castellano, catalán, euskera o galle-

${ }^{5}$ En este sentido, la Ley 54/2007 de Adopción Internacional, ha supuesto un impulso en esta toma de conciencia al reconocer en el art. 12 el derecho a facilitar a las personas adoptadas información sobre sus orígenes. 
go, hablan de cómo un señor convenció o pagó a sus padres para que los entregaran, en ocasiones con la promesa de que tendrían noticias frecuentemente o de que volverían con ellos cuando finalizaran sus estudios (p. 2).

\section{Los menores adoptados como sujetos de promoción}

Exponíamos como con la Convención, la nueva visión implicaba un mayor reconocimiento del niño y la niña como personas y como ciudadanos y ciudadanas, sujetos de derechos al igual que todos los seres humanos, sin discriminación por razón de edad. En este cambio de perspectiva, la infancia no sólo tienen derechos sociales, relativos a su superviviencia, atención, educación y protección, sino que también supone el reconocimiento por primera vez en la historia de sus derechos civiles y políticos, contenidos en los artículos del 12 al 16 de la Convención: la participación expresa el derecho a tener voz con un peso específico, tanto individual como colectivamente. El artículo 12 es clave al considerar que el niño es un ser creativo, protagonista y copartícipe en la sociedad. Diferentes actuaciones como presentar denuncias, testificar, derecho a ser oídos, ser escuchados en los procesos de separación y divorcio, etc. son actualmente una realidad y sin duda, un avance que destierra la idea de anularlos por completo.

Sin embargo esta situación es polémica, nos hallamos ante el debate abierto sobre si el menor es competente y tiene capacidad de ejercer sus derechos. Conceptos como capacidad de juicio, capacidad de obrar, madurez psíquica, madurez anticipada, semicapacidad o discernimiento entre otros, son difíciles de definir y los legisladores parecen encontrar la respuesta en función del factor de la edad, indicador que es relativo, impreciso y poco fiable (Casas, 1998). Desde la perspectiva del niño y niña, las tendencias que se han iniciado con la Convección tardarán en imponerse debido a los obstáculos estereotipados tan arraigados que subestiman la competencia de los niños y niñas y la capacidad de responsabilizarse de sus actos.

El papel de la participación del niño es uno de los principios fundamentales en la Carta Africana, y en el Convenio de La Haya (art. 4.d.), teniendo en cuenta la edad y el grado de madurez del niño, se plantea la necesidad de recono- cer su consentimiento de que la adopción internacional podría ser una medida de protección.

La situación del menor en los procesos adoptivos, objeto de este trabajo, comprende el hecho de tener en cuenta sus opiniones, su autonomía, voluntad, y respetar su ámbito de decisión en aquellas situaciones que pudieran afectarles. Nos referimos a la necesidad de informarle, de tener en cuenta sus deseos, opiniones y recabar su consentimiento. Siguiendo a Gómez, que el menor esté de acuerdo con la medida que se va a tomar, además de ser un derecho que le asiste, resulta fundamental para el éxito de la adopción. Debemos valorar la conveniencia de la medida en relación con el interés superior del menor y tratar de minimizar las posibilidades de fracaso (Gómez, 2010).

Cuando se declara la condición de adoptable, debemos consultarle y preguntarse si está dispuesto a aceptar la adopción, valorar la capacidad para adaptarse a un cambio tan importante como éste, conocer si está preparado para recibir a unos nuevos padres y una nueva familia, y en su caso prepararlo para la integración definitiva en ella (ídem).

Recordemos en relación al consentimiento, que el país de origen del menor debe garantizar que la familia biológica o las instituciones protectoras de menores cuando los niños estaban a su cargo, ha dado su consentimiento libremente, tras haber sido informada y comprende las consecuencias, y asesorada del carácter irrevocable de la adopción, sin que haya habido ningún tipo de pago o compensación. Siguiendo la normativa de nuestro país en ámbito de la adopción nacional, el juez debe oír la opinión del menor acerca de la solicitud de adopción siempre que tenga al menos, 12 años de edad (art.177.1 Código Civil); si el adoptado es menor de 12 años no se requiere su consentimiento, si bien se impone el deber de oírlo (art. 177.3.3 ${ }^{\circ}$ Código Civil). Lo que implica que no puede obviarse la audiencia del menor y de esta manera adquiere un papel esencial y protagonista en la determinación de su filiación, en coherencia con el estatus de persona sujeto de derechos.

\section{Consideraciones finales}

Desde el punto de vista del menor, la adopción constituye una medida de protección, que deberá regirse por la búsqueda del interés superior del niño y el respeto a sus derechos. 
A diferencia de la paternidad biológica, considerada de ámbito de lo privado, la adopción es un recurso social, competencia de los poderes públicos. Atrás quedan los tiempos cuando el derecho de los padres a tener un hijo prevalecía sobre el derecho de los niños y niñas a tener una familia.

El interés superior del menor, y la aplicación de la adopción como último recurso, son los dos principios guía, tal y como lo expresan las convenciones internacionales y las legislaciones internas de los países.

Sin embargo, el cambio normativo centrado en el protagonismo de los niños y niñas, aún queda pendiente de su traducción en la práctica de la filiación adoptiva, al igual que la concepción que la sociedad en general aún tiene sobre la adopción internacional.
Del análisis de Berástegui, basado en el de Hoksbergen (2010), sobre la generación actual de padres adoptantes en España, a la cual denomina la «generación consumista», que ejerce una presión significativa sobre los países, siendo la demanda de los países occidentales superior a la oferta de niños y niñas con adoptabilidad, y tiene como resultados casos de adopciones irregulares y fraudulentas. Desde diferentes foros académicos, investigadores, organizaciones en defensa de los derechos de la infancia se han denunciado tales prácticas. Se impone como imperativo ético que los poderes públicos siendo responsables de la adopción internacional como un recurso social, adopten medidas garantes de los derechos y bienestar de los niños y niñas.

\section{Referencias bibliográficas}

Alston, P. y Gilmour-Walsh, B. (1999). El interés superior del niño. Hacia una síntesis de los Derechos del Niño y de los Valores Culturales. Madrid: Ministerio de Trabajo y Asuntos Sociales y UNICEF.

Arruabarrena, Ma.I. y De Paul, J. (1994). Maltrato a los niños en la familia. Evaluación y Tratamiento. Madrid: Pirámide.

Berástegui, A. (2005). La adaptación familiar en adopción internacional: Una muestra de adoptados mayores de tres años en la Comunidad de Madrid. Madrid: Consejo Económico y Social de la Comunidad de Madrid.

Berástegui, A. (2009). La adopción en España: un punto de inflexión. AFIN-Newsletter, 5, 1-9. Disponible en: http://.www.afin.org.es (30 de Julio de 2009).

Berástegui, A. (2010). Adopción internacional: ¿solidaridad con la infancia o reproducción asistida? Revista de Psicologia, Ciències de l'Educació i de l'Esport, 27,15-38. Recuperado de http://www.raco.cat/index.php/Aloma.

Casalilla, J.A. (2010). La prevención en post-adopción, una mirada al inicio del proceso: El caso de Haití. Recuperado de http:// www.psicomed.es/la-prevencion-en-post- adopcion-una-mirada-al-inicio-del-proceso-el-caso-de-haiti (30 enero de 2011).

Casas, F. (1998). Infancia: perspectivas psicosociales. Barcelona: Paidós.

Cantwell, N. (2003). La Adopción Internacional. Un comentario sobre el número de niños «adoptables» y el número de personas que buscan adoptar internacionalmente. Protección Internacional del Niño. En Boletín de los Jueces para la Convención de la Haya, 5, 1-3. Recuperado de www.hcch.net/upload/spring2003_s.pdf

Gómez Bengoechea, B. (2010). Adoptabilidad. AFIN-Newsletter, 11, 1-17. Disponible en: http:// www.afin.org.es (30 de Enero de 2009).

Marre, D. (2004). La adopción internacional y las asociaciones de familias adoptantes; un ejemplo de sociedad civil virtual. Scripta Nova 170 (4), 1-15. Disponible en: www.ub.edu/geocrit/ nova.htm

Marre, D. (2010). Adopción Familiar: una visión antropológica. En F. Loizaga (ed.) Adopción Hoy. Nuevos desafios, nuevas estrategias (pp. 139.176). Bilbao: Mensajero. Mezmur, B. D. (2009). La adopción internacional como medida de último recurso en África: promover los derechos del niño, y no el derecho a un niño. Sur-Revista Internacional de Derechos Humanos, 10,83-105. Disponible en: www.surjournal.org (23 de octubre de 2010).

Mezmur, B. D. (2010). Los pecados de los «salvadores: el tráfico de niños en el ámbito de la adopción internacional en África». Documento informativo, 2, 1-35. Comisión Especial del Conve- 
nio de La Haya relativo a la Protección del Niño y a la Cooperación en materia de Adopción Internacional. Disponible en www.hcch.net (12 de Enero de 2011).

Montané, M.J. (1996). La evolución de la adopción internacional en España. Anuario de Psicología, 71, 23-35.

Piloti, F. (2000). Globalización y Convención sobre los Derechos del Niño: El Contexto del Texto. Washington: Organización de los Estados Americanos.

Saclier, Ch. (1999). Los niños y la adopción: qué derechos y de quién. Disponible en http:// www.iin.oea.org/Adopcion.pdf (1 de marzo 2011).

San Román, B. (2008). 2008. Más de seis expedientes por cada adopción. Disponible en http://www.parasaber.com/familia/adopciones/adopción-internacional/articulo/adopcion-internacional- unicef-2008-expedientes/ 17097(consultado en marzo de 2011).

San Román, B. (2009). La adopción internacional: el imperativo moral de una reforma urgente. AFIN-Newsletter, 6, 1-10. Disponible en: http://.www.afin.org.es (30 de Septiembre de 2009).

Centro Internacional de Referencia para los Derechos del Niño Privado de Familia del Servicio Social Internacional. (2004).En el interés superior del niño, ¿qué oferta para responder a qué demanda? Boletín Mensual, 65,1-2. Disponible en: www.iss-ssi.org (23 de Marzo de 2009).

Centro Internacional de Referencia para los Derechos del Niño Privado de Familia del Servicio Social Internacional. (2008). Revelación de los mitos relativos al número de niños adoptables y necesidad de una mayor precisión en el momento de determinar quién es adoptable». Boletín Mensual, 10, 1-3. Disponible en: www.iss-ssi.org (23 de Marzo de 2009).

Centro Internacional de Referencia para los Derechos del Niño Privado de Familia del Servicio Social Internacional. (2008a).Diversificación de los países de origen y aumento de la edad de los niños adoptados en un paisaje de la adopción internacional siempre tenso. Boletín Mensual, 7-8, 1-2. Disponible en: www.iss-ssi.org (3 de Enero de 2010).

Centro Internacional de Referencia para los Derechos del Niño Privado de Familia del Servicio Social Internacional. (2008b). Consecuencias del aumento de las adopciones internacionales y sensibilización creciente sobre las necesidades en una región: el ejemplo de África. Boletín Mensual,5,1-2. Disponible en: www.iss-ssi.org (3 de Enero de 2010).

UNICEF. (1999). Adopción Internacional. Innocenti Digest, 4, 1-24.

Verhellen, E. (1992). Los derechos del niño en Europa. Infancia y Sociedad, 15, 37-60.

Winterberger, H. (1994). Los niños y la sociedad. Materiales de Trabajo, 24, 53-91. 